\title{
Growth Regulatory Effects and Soil Concentration of Controlled-release Trifluralin Applied to Roots of Yellow poplar and Red Oak
}

\author{
Thomas J. Tworkoski ${ }^{1}$ \\ U.S. Department of Agriculture, Agricultural Research Service, Appalachian Fruit Research Station, \\ Kearneysville, WV 25430 \\ Michael E. Engle ${ }^{2}$ and Peter T. Kujawski ${ }^{2}$ \\ U.S. Department of Agriculture, Agricultural Research Service, Foreign Disease-Weed Science, Frederick, \\ MD 21702
}

Additional index words. biobarrier, Liriodendron tulipifera, Quercus rubra, root inhibition

\begin{abstract}
A polypropylene fabric containing control-release pellets of the herbicide, trifluralin, can be oriented in the soil to regulate the distribution of plant roots. In 1990, trenches were dug near 10-year-old red oak (Quercus rubra $\mathrm{L}$.) and 10year-old yellow poplar (Liriodendron tulipifera $\mathrm{L}$.) and fabric containing trifluralin control-release pellets and polypropylene fabric alone were installed vertically to redirect root growth. Roots grew alongside trifluralin fabric and fabric alone and did not penetrate either fabric 38 months after installation. Shoot growth of yellow poplar was reduced about $47 \%$ each year by the trifluralin fabric treatment compared to control. Red oak shoot growth was not affected by trifluralin fabric. Leaf water potential was not affected by treatment in either species. Trifluralin residues in trifluralin fabric decreased from $23.3 \%$ to $22.0 \%$ from July 1990 to October 1993. During this time, trifluralin levels increased from 0.4 to $3.6 \mathrm{mg} \cdot \mathrm{kg}^{-1}$ in soil sampled 0 to $15 \mathrm{~cm}$ below trifluralin fabric. These results suggest that controlled-release trifluralin will provide persistent inhibition of root and shoot growth of some species and will not migrate significantly in the soil. Chemical names used: $\alpha, \alpha, \alpha$-trifluoro-2,6-dinitro- $N$ - $N$-dipropyl-p-toluidine (trifluralin).
\end{abstract}

Tree root growth can cause economic and environmental problems by penetrating sewage pipes, upheaving sidewalks, and disturbing clay barriers over landfills (Van Voris et al., 1988). Trifluralin fabric (Biobarrier, Reemay, Old Hickory, Tenn.) can inhibit and redirect root growth. Trifluralin fabric consists of polypropylene fabric with pellets attached at equal intervals (Burton et al., 1986, 1991). The pellets are made of polyethylene and carbon impregnated with the herbicide, trifluralin. Trifluralin fabric is produced as long sheets in widths up to $149 \mathrm{~cm}$. It is buried in soil in a horizontal or vertical orientation. Trifluralin is released slowly from the pellets and inhibits root growth by disrupting cell division (Weed Science Society of America, 1989). Controlledrelease trifluralin formulations reduce volatilization and chemical decomposition and, therefore, increase its longevity and effectiveness (Van Voris et al., 1988; White and Schreiber, 1984). There is little information pertaining to trifluralin soil residues or longevity when trifluralin fabric is buried in soils receiving high annual precipitation.

Efficacy of trifluralin fabric varies. One year after installation, trifluralin fabric was not penetrated by roots of red maple (Acer rubrum L.) and willow oak (Quercus phellos L.) (Gilliam et al., 1992). Roots of American sycamore (Platanus occidentalis L.) and Bradford flowering pear (Pyrus calleryana Decne.) did penetrate trifluralin fabric. In another study, rhizomes but not roots of

Received for publication May 1995. Accepted for publication $18 \mathrm{Dec}$. 1995. Use of a trade name does not constitute a guarantee or warranty by the U.S. Dept. of Agriculture and does not imply their approval to the exclusion of other products that may also be suitable. We thank Jerry Dunaway and Jose Solar for their ideas and assistance in measuring trifluralin residues. Thanks to Reemay, Inc., for their financial support. The cost of publishing this paper was defrayed in part by the payment of page charges. Under postal regulations, this paper therefore must be hereby marked advertisement solely to indicate this fact.

${ }^{1}$ Plant physiologist.

${ }^{2}$ Biological laboratory technician. bamboo (Phyllostachys rubromarginata) and bahiagrass (Paspalum notatum Fluegge) grew around trifluralin fabric 2 years after installation (Dosskey, 1991). In that study, loblolly pine (Pinus taeda L.) roots penetrated the trifluralin fabric. Most experiments with trifluralin fabric have been conducted with plants in pots over a short time; therefore, knowledge of the response of established trees to trifluralin fabric is necessary to determine long-term effects.

Trifluralin fabric installation requires digging a trench close to a tree trunk; however, the trenching and subsequent root inhibition may alter the function of a tree root and affect tree shoot growth. Dosskey et al. (1991) found reduced foliar N, Ca, and Mg in plants whose roots were exposed to trifluralin fabric. Water uptake is a crucial function of plant roots; but no reports on the effect of trifluralin fabric on plant water status are available.

This experiment was conducted to elucidate the effects of trifluralin fabric on well-established trees during 3 years. The objectives were to 1 ) determine the inhibitory effect of trifluralin fabric on root and shoot growth; 2) evaluate the water status of trees whose roots were exposed to trifluralin fabric; and 3) determine the longevity of the effect of trifluralin fabric on selected trees and trifluralin movement through the soil over time.

\section{Materials and Methods}

The experiment was conducted in a 0.7-ha grove of yellow poplar and northern red oak trees located in Frederick, Md. Yellow poplars were planted in 1981 and were about $7.6 \mathrm{~m}$ tall in 1990. Northern red oaks were planted in 1981 and were about $6.1 \mathrm{~m}$ tall in 1990. Trees were planted on a $6 \times 6 \mathrm{~m}$ spacing in Duffield silt loam (Ultic Hapludalfs; fine-loamy, mixed, mesic) soil with a $\mathrm{pH}$ of 6.0 and an organic matter content of $3.1 \%$. Orchard grass (Dactylis glomerata L.) occupied the ground surface beneath the trees and it was maintained at a height of $13 \mathrm{~cm}$. 
Trifluralin fabric and polypropylene fabric alone were installed on 31 July 1990. Two parallel ditches about $30 \mathrm{~cm}$ deep, $10 \mathrm{~cm}$ wide, and $4 \mathrm{~m}$ long were dug on opposite sides of each tree. Each ditch was $1 \mathrm{~m}$ from the tree trunk so that one tree was centrally located between the trenches. Trifluralin fabric and fabric alone $(30 \mathrm{~cm} \times 4 \mathrm{~m})$ were held in place in a vertical position while soil was backfilled into the trench (Fig. 1A). Each experimental tree was surrounded by buffer trees. Four additional 6-m trenches were dug about $12 \mathrm{~m}$ from the experimental trees and fifteen $30 \times 30-\mathrm{cm}$ trifluralin fabric pieces were placed vertically in each trench. These trifluralin fabric segments were used to measure trifluralin residues in fabric and in soil near the fabric at the end of each growing season.

Leaf water potential, soil moisture, shoot growth, precipitation, and air temperature were measured during the growing seasons from July 1990 through October 1993. Water potential of leaf disks was selected as the most useful index of plant water stress (Kramer, 1983). Leaf water potential was determined with thermocouple psychrometers (J.R.D. Merrill, Logan, Utah) each week using leaf disks subsampled from branches used to measure shoot elongation in each experimental tree. Soil moisture content below each tree was determined by weighing soil collected with a soil probe from 0 to $15 \mathrm{~cm}$ and 15 to $30 \mathrm{~cm}$ depths, drying at $80 \mathrm{C}$ for 2 days, and dividing the difference between wet and dry weight by dry weight. Soil moisture content was determined monthly during the growing season.

Shoot elongation and the number of internodes were measured monthly during the growing season on three branches per tree. Branches selected were halfway between the top and bottom of the crown, receiving full sunlight, and not physically restricted.

Root penetration of the fabric treatments was evaluated in September 1991, 1992, and 1993. Sites of root evaluation were selected randomly so that both trenches from each tree were sampled each year and each sampling site was evaluated once during the experiment. All sampling sites were within $1.5 \mathrm{~m}$ of the tree trunk. Soil was excavated from the fabric on the side opposite the tree to expose a $900-\mathrm{cm}^{2}$ segment of intact fabric in situ. Number of root penetrations and general root condition were evaluated. The soil was then backfilled into the trench covering the fabric. All fabric from trifluralin fabric and fabric alone treatments were excavated in October 1993 to measure root penetration. Also at that time, two tree cores (Haglof increment borer; Forestry Suppliers, Jackson, Miss.), perpendicular to each other and parallel to the ground were taken from each tree trunk $1 \mathrm{~m}$ above the ground. Annual ring growth was measured for each core and the two values were averaged per tree.

Trifluralin residues were measured from the soil and fabric in four trenches away from experimental trees. At the end of each growing season, soil was sampled with a hand soil probe. To reduce the possibility of cross-contamination, the probe was cleaned between samples and residue analysis was on soil from the inner portion of the extracted plug. Soil adjacent to and within $1 \mathrm{~cm}$ of a $900-\mathrm{cm}^{2}$ trifluralin fabric segment was sampled 0 to $15 \mathrm{~cm}$ and 15 to $30 \mathrm{~cm}$ beneath the soil surface. Soil was excavated and the $900-\mathrm{cm}^{2}$ trifluralin fabric segment was removed. Soil directly below trifluralin fabric was then sampled with the soil probe at depths of 30 to $45 \mathrm{~cm}$ beneath the soil surface (i.e., directly below the trifluralin fabric) and 45 to $60 \mathrm{~cm}$ below the soil surface. Each season, six trifluralin fabric segments and six sets of soil samples were measured for trifluralin residues. Soil samples within $3 \mathrm{~m}$ of trifluralin fabric served as controls.

In addition to trifluralin content of a vertical soil column, the horizontal distribution of trifluralin from trifluralin fabric was measured in soil increments removed with a soil probe from the vertical soil surface exposed when trifluralin fabric was removed. Three horizontal probes were performed in 1992 and 1993. All soil and trifluralin fabric samples were frozen until analyzed with a method similar to that of Burton et al. (1991). Trifluralin residues in 1-g aliquots of soil and trifluralin fabric were extracted in $10 \mathrm{ml}$ methanol for $24 \mathrm{~h}$, purified with high-performance liquid chromatography using a $\mathrm{C}_{18}$ column (Waters Associates Inc., Milford, Mass.) and a methanol/water gradient from $76 \%$ to $90 \%$, and quantified, based on absorbance at $273 \mathrm{~nm}$.

Trifluralin residue in methanol extracts was confirmed by gas chromatography-mass spectroscopy (GC-MS). A GC (model 5890; Hewlett Packard, Avondale, Pa.) with a Sup-Herb (Supelco, Bellefonte, Pa.) column (50-kPa head pressure) were used to separate trifluralin with the following conditions: injection tem-

Table 1. Shoot growth and width of annual rings of yellow poplar after installing (July 1990) polypropylene fabric alone and trifluralin fabric from 1991 to 1993.

\begin{tabular}{|c|c|c|c|c|}
\hline Year & Treatment & $\begin{array}{l}\text { Shoot } \\
\text { length } \\
(\mathrm{cm})\end{array}$ & $\begin{array}{c}\text { Stem } \\
\text { internodes } \\
\text { (no.) }\end{array}$ & $\begin{array}{c}\text { Annual ring } \\
\text { width } \\
(\mathrm{mm})\end{array}$ \\
\hline \multirow[t]{3}{*}{1991} & Control & 27.7 & 14.8 & 6.1 \\
\hline & Fabric alone & 26.3 & 14.3 & 5.8 \\
\hline & Trifluralin fabric & 17.6 & 13.3 & 5.0 \\
\hline $\operatorname{LSD}(0.05)$ & & 6.7 & NS & NS \\
\hline \multirow[t]{3}{*}{1992} & Control & 24.3 & 14.1 & 11.3 \\
\hline & Fabric alone & 26.5 & 14.8 & 10.0 \\
\hline & Trifluralin fabric & 12.5 & 13.5 & 9.6 \\
\hline $\operatorname{LSD}(0.05)$ & & 10.4 & NS & NS \\
\hline \multirow[t]{3}{*}{1993} & Control & 24.3 & 13.3 & 8.1 \\
\hline & Fabric alone & 26.5 & 14.3 & 7.3 \\
\hline & Trifluralin fabric & 12.7 & 12.3 & 7.2 \\
\hline $\operatorname{LSD}(0.05)$ & & 10.3 & NS & NS \\
\hline \multirow[t]{3}{*}{ Total } & Control & 76.2 & 42.1 & 25.6 \\
\hline & Fabric alone & 79.3 & 43.4 & 23.1 \\
\hline & Trifluralin fabric & 42.8 & 39.1 & 21.7 \\
\hline LSD $(0.05)$ & & 25.3 & NS & NS \\
\hline
\end{tabular}

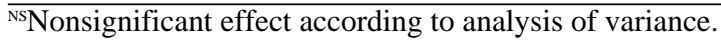


perature 230C; oven temperature gradient from 60 to 290 at $14 \mathrm{C} /$ min. A MS (model 5971; Hewlett Packard) in the selected ion mode was used to quantify trifluralin for fragment ion $306(\mathrm{~m} / \mathrm{z})$ at retention time $15.2 \mathrm{~min}$. Average trifluralin recoveries were $47.5 \%$ $(2.3 \% \mathrm{cV})$. Repeatable sensitivity was obtained with $5 \mathrm{ng}$ of trifluralin.

The experimental design was completely randomized with three trifluralin fabric-trench treatments: 1) trifluralin fabric in a trench (trifluralin fabric), 2) polypropylene fabric without trifluralin in a trench (fabric alone), and 3) no fabric-no trench (control). Each treatment per species was replicated four times for a total of 24 trees (experimental units). Analysis of trifluralin residues was also based on a completely randomized design but with six replications per year. Mean separation was based on Fisher's protected LSD (Steel and Torrie 1960).

\section{Results and Discussion}

Shoot elongation of yellow poplar was reduced by trifluralin fabric about $36 \%$ in 1991 and $48 \%$ in 1992 and 1993 compared with the control and fabric alone treatments (Table 1). These results are similar to Dornai et al. (1991), who found a $37 \%$ decrease in stem length in cotton (Gossypium hirsutum L.). Most growth occurred during May and June when control trees grew significantly more than trifluralin fabric trees (data not shown). Trunk diameter growth and number of internodes were not affected by treatment in yellow poplar. Red oak shoot elongation and trunk diameter were not affected by trifluralin fabric or fabric alone (data not shown).

Yellow poplar had many thick roots that appeared to grow quickly to form a mass of root material to the tree side of the trifluralin fabric (Fig. 1B). Red oak roots were finer and less frequent, but there was a substantial number of contacts with the trifluralin fabric. With both species, root tips became malformed and necrotic or they grew beside the trifluralin fabric until the pathway over or under the trifluralin fabric became available. Root tips often became clubbed, as reported by Olson et al. (1984) in wheat (Triticum aestivum L.). In yellow poplar, necrotic lesions on the surface of roots near trifluralin fabric suggested that trifluralin caused root injury. No root injury was observed in roots growing near fabric alone.

Roots of either species would occasionally grow over the trifluralin fabric if it was not within $1 \mathrm{~cm}$ of the soil surface (Fig. 1B). Despite the differences in root abundance and morphology, neither species penetrated the trifluralin fabric or the fabric alone. All trifluralin fabric and fabric alone were excavated in October 1993, more than 3 years after installation, and no root penetration was observed at any place in the thirty-two 4-m-long segments. Dosskey et al. (1991) reported that only fine roots of bahiagrass, bamboo, and loblolly pine penetrated fabric and few roots could penetrate trifluralin fabric. Burton et al. (1991) reported that no roots penetrated trifluralin fabric, although soybean (Glycine $\max$ L. Merr.) was more tolerant than bermudagrass (Cynodon dactylon (L.) Pers.). Evidently, capacity for root penetration of trifluralin fabric is species related and requires consideration before installation.

Fig. 1. (A) Yellow poplar tree with trifluralin fabric installation on July 31, 1990. The experimental tree (a) is $1 \mathrm{~m}$ from the trifluralin fabric. (B) Yellow poplar tree with roots exposed during trifluralin fabric removal in October 1993. Some roots grew over the trifluralin fabric (a) but most grew alongside the fabric (b).
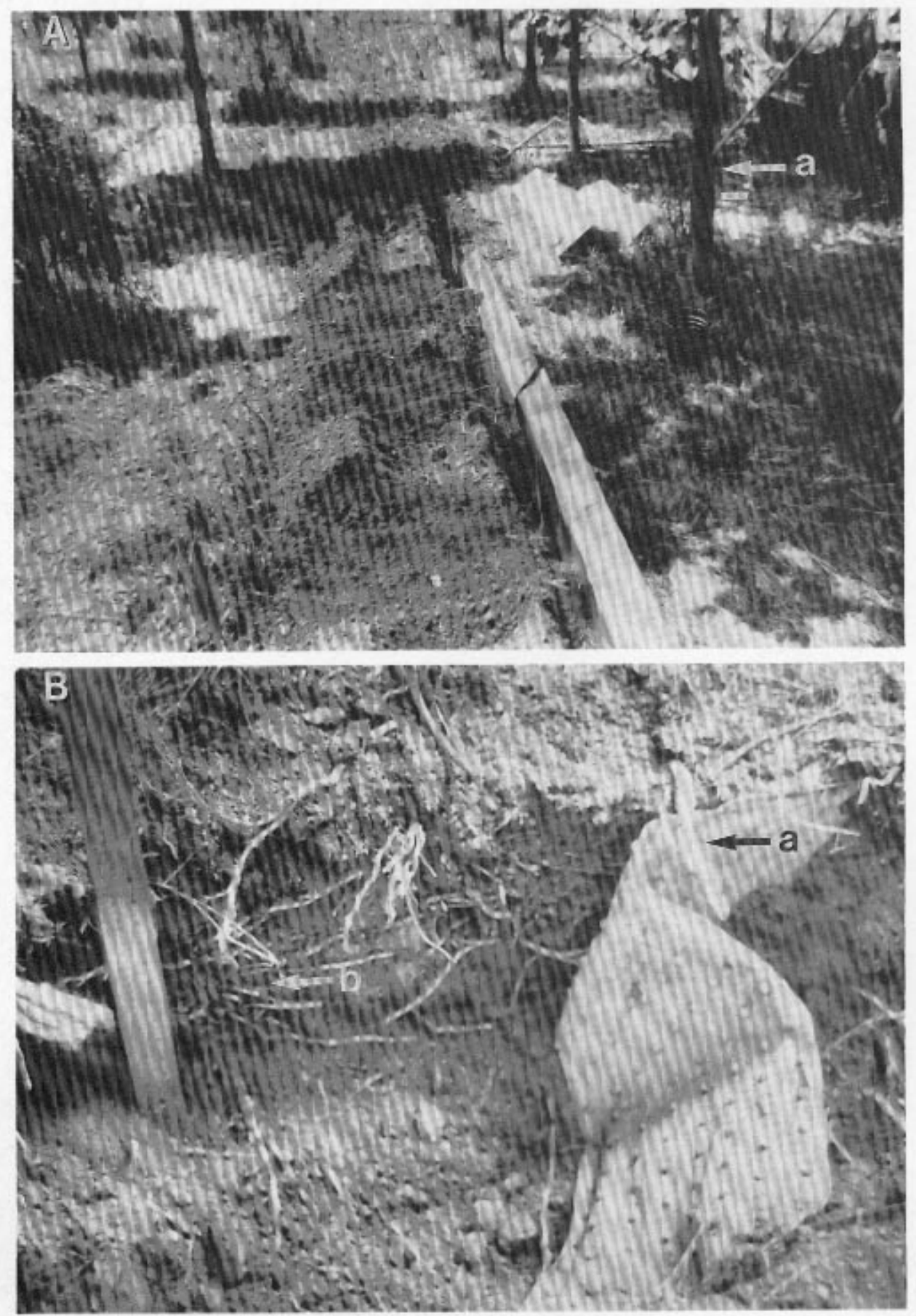
Table 2. Trifluralin residue in soil from trifluralin fabric plots.

\begin{tabular}{cc}
\hline $\begin{array}{l}\text { Main } \\
\text { effect }^{\mathrm{z}}\end{array}$ & $\begin{array}{c}\text { Trifluralin concn } \\
\left(\mathrm{mg} \cdot \mathrm{kg}^{-1}\right)\end{array}$ \\
\hline $\begin{array}{c}\text { Depth from surface (cm) } \\
\text { 0-15 }\end{array}$ & 4.7 \\
$15-30$ & 14.3 \\
$30-45$ & 3.6 \\
$45-60$ & 2.1 \\
LSD (0.05) & 5.0 \\
Species & \\
Red oak & 6.6 \\
Yellow poplar & 5.4 \\
LSD (0.05) & $\mathrm{NS}$ \\
Year & \\
1990 & 1.5 \\
1991 & 4.8 \\
1992 & 10.8 \\
1993 & 4.9 \\
LSD (0.05) & 5.1
\end{tabular}

$\overline{\mathrm{z} T h e r e}$ were no significant interactions. Depths are averaged across species and year; species are averaged across depth and year; years are averaged across depth and species.

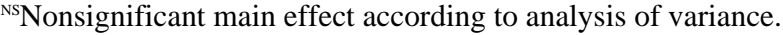

There was no evidence that either trifluralin fabric or fabric alone affected leaf water potential compared to control trees of either species (data not shown). Yellow poplar leaves consistently had more moisture (data not shown) and less negative leaf water potential than red oak leaves. Typical leaf water potentials of yellow poplar and red oak during July averaged -0.8 and $-1.6 \mathrm{MPa}$, respectively. As each growing season progressed leaf water potential became more negative for both species (data not shown).

Growth of both red oak and yellow poplar was consistent from year to year (Table 1), even with precipitation differences. Annual precipitation in 1991 was about $63 \%$ that of other years, but leaf water potential was similar in 1991 compared to other years (data not shown). Evidently, the trees were able to obtain necessary water despite root pruning, root inhibition, and decreased precipitation.

Soil trifluralin residues varied significantly with depth and year (Table 2). Trifluralin concentration was greatest $\left(14.3 \mathrm{mg} \cdot \mathrm{kg}^{-1}\right)$ at the 15 to $30 \mathrm{~cm}$ depth in soil sampled adjacent to trifluralin fabric. Burton et al. (1991) also reported the highest trifluralin concentrations $\left(32 \mathrm{mg} \cdot \mathrm{kg}^{-1}\right)$ in soil adjacent to trifluralin fabric. Significantly less trifluralin occurred at the 0 to $15 \mathrm{~cm}$ depth $\left(4.7 \mathrm{mg} \cdot \mathrm{kg}^{-1}\right)$. Abundant soil water, high temperature, and microbial activity can facilitate trifluralin volatilization and degradation (Burton et al., 1991; Carter and Camper, 1975; Messersmith et al., 1971). In the current experiment, soil moisture varied from $10 \%$ to $27 \%$, but soil from the 0 to $15 \mathrm{~cm}$ depth consistently had $2 \%$ more moisture than soil from the 15 to $30 \mathrm{~cm}$ depth. Trifluralin may have volatilized or degraded more readily at the shallower depth.

Downward migration of trifluralin was minimal (Table 2). Trifluralin concentration at 45 to $60 \mathrm{~cm}$ depth (i.e., 15 to $30 \mathrm{~cm}$ below the bottom of the trifluralin fabric) was $2.1 \mathrm{mg} \cdot \mathrm{kg}^{-1}$. Grover et al. (1988) found no trifluralin downward movement at $10 \mathrm{~cm}$ below the soil surface 160 days after incorporating trifluralin to a $5 \mathrm{~cm}$ depth. They reported $23.7 \%$ trifluralin loss due to volatilization. In the current experiment, volatilization losses presumably were reduced by the controlled release from the trifluralin fabric pellets and by the burial depth of the trifluralin fabric.
During the first 2 months after installation, the trifluralin residue in pellets on fabric did not change (data not shown). Trifluralin soil residues were greater in 1991, 1992, and 1993 compared with 1990 (Table 2). Trifluralin concentration increased from $1.5 \mathrm{mg} \cdot \mathrm{kg}^{-1}$ in 1990 to $4.9 \mathrm{mg} \cdot \mathrm{kg}^{-1}$ in 1993 . There also was decreased trifluralin in trifluralin fabric during this time, suggesting that trifluralin was being released into the soil. These results generally agree with Burton et al. (1991), who found trifluralin concentration to equilibrate between trifluralin fabric and soil within 8 months after installation. The high trifluralin concentration in $1992\left(10.8 \mathrm{mg} \cdot \mathrm{kg}^{-1}\right)$ may have resulted from increased leaching as a result of greater precipitation during the growing season in 1992 compared with 1991 and 1993 (data not shown).

Trifluralin concentrations lateral to trifluralin fabric were greatest within $2 \mathrm{~cm}$ of trifluralin fabric and approached zero between 2 and $6 \mathrm{~cm}$ from trifluralin fabric (Fig. 2). These results agree with Gilliam et al. (1992), who determined the effective range to be about $5 \mathrm{~cm}$ from trifluralin fabric. In the current experiment, lateral migration of trifluralin was characterized by the following quadratic regression: trifluralin concentration $\left(\mathrm{mg} \cdot \mathrm{kg}^{-1}\right)=60.12-$ 33.39 (lateral distance from trifluralin fabric in $\mathrm{cm}$ ) +4.18 (lateral distance from trifluralin fabric in $\mathrm{cm})^{2}\left(r^{2}=0.77\right)$.

Little change in trifluralin concentrations was detected in the trifluralin fabric (23.3\%, w/w, in 1990 and $22.0 \%$ in 1993). These results suggest that trifluralin fabric should remain active for many years when placed in the soil under similar environmental conditions.

Trifluralin fabric and fabric alone restricted root growth of red oak and yellow poplar. In general, shoot growth of red oak was not affected by treatment but that of yellow poplar was reduced. Throughout the experiment, branch elongation was significantly less in yellow poplar treated with trifluralin fabric than control or fabric alone. Leaf water potential of treated trees was not related to treatment and could not explain differences observed in shoot growth. Trifluralin is not readily translocated in plants (Weed Science Society of America, 1989) and it is not likely that trifluralin directly inhibited shoot growth. It is possible that trifluralin fabric interfered with mineral uptake in the large, rapidly growing root system of yellow poplar. Olson et al. (1984) found reduced $\mathrm{N}$, $\mathrm{P}$, and $\mathrm{K}$ levels in shoots of wheat whose roots were exposed to

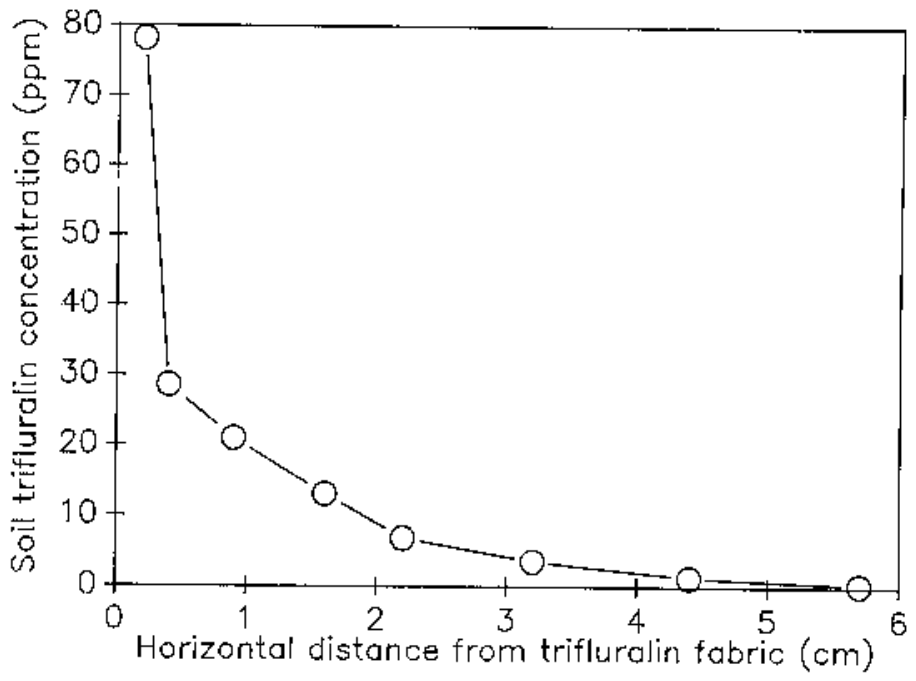

Fig. 2. Distribution of trifluralin in soil with increasing horizontal distance from trifluralin fabric. Trifluralin concentration $\left(\mathrm{mg} \cdot \mathrm{kg}^{-1}\right)=60.12-33.39$ (lateral distance from trifluralin fabric in $\mathrm{cm}$ ) +4.18 (lateral distance from trifluralin fabric in $\mathrm{cm})^{2}$. 
trifluralin. Abnormal root growth in yellow poplar may also have interfered with root-produced phytohormones that influence shoot development. These results suggest that trifluralin fabric will affect tree species differentially, which is an important consideration in its use.

\section{Literature Cited}

Burton, F.G., D.A. Cataldo, P. Van Voris, W.E. Skiens, R.D. Griggs, O.D. Decker, D.C. Adriano, and C.E. Murphy. 1991. Field validation and performance specifications of a long-term controlled-release herbicide delivery system for multiple-year control of root growth. J. Controlled Release 15:15-27.

Burton, F.G., W.E. Skiens, J.F. Cline, D.A. Cataldo, and P. Van Voris. 1986. A controlled-release herbicide device for multiple-year control of roots at waste burial sites. J. Controlled Release 3:47-54.

Carter, Jr., G.E. and N.D. Camper. 1975. Soil enrichment studies with trifluralin. Weed Sci. 23:71-74.

Dornai, D., Z. Gerstl, Y. Chen, and U. Mingelgrin. 1991. Trifluralin effects on the development of cotton in arid zone soils. Weed Res. 31:375-384.

Dosskey, M.G., D.C. Adriano, C.E. Murphy, and J.C. Corey. 1991. Effectiveness of a slow-release herbicide system for control of root intrusions into buried hazardous waste. Haz. Waste Haz. Materials 8:293-301.
Gilliam, C.H., D.J. Eakes, P.R. Knight, and J.A. Reeder. 1992. Biobarrier restricts root growth. Highlights of agricultural research, Alabama Agr. Expt. Sta. 39:5.

Grover, R., A.E. Smith, S.R. Shewchuk, A.J. Cessna, and J.H. Hunter. 1988. Fate of trifluralin and triallate applied as a mixture to a wheat field. J. Environ. Qual. 17:543-549.

Kramer, P.J. 1983. Water relations of plants. Academic Press, New York. p. $374-389$.

Messersmith, C.G., O.C. Burnside, and T.L. Lavy. 1971. Biological and non-biological dissipation of trifluralin from soil. Weed Sci. 19:285290.

Olson, B.M., R.B. McKercher, and E.H. Halstead. 1984. Effects of trifluralin on root morphology and mineral status of wheat (Triticum aestivum) seedlings. Weed Sci. 32:382-387.

Steel, R.G.D. and J.H. Torrie. 1960. Principles and procedures of statistics. McGraw-Hill, New York. p. 106-107.

Van Voris, P., D.A. Cataldo, C.E. Cowan, N.R. Gordon, J.F. Cline, F.G. Burton, and W.E. Skeins. 1988. Long-term controlled release of herbicides, p. 222-240. In: B. Cross and H.B. Scher (eds.). Pesticide formulations: Innovations, and developments. Amer. Chem. Soc. Symp. Ser. 371.

White, M.D. and M.M. Schreiber. 1984. Herbicidal activity of starch encapsulated trifluralin. Weed Sci. 32:387-394.

Weed Science Society of America. 1989. Herbicide handbook. 6th ed. Weed Sci. Soc. Amer., Champaign, Ill. p. 252-256. 